\section{A practical skill one day medical emergencies course for dentists and DCPs}

\author{
M. C. Balmer ${ }^{1}$ and L. P. Longman ${ }^{2}$
}

CORE VERIFIABLE CPD PAPER
IN BRIEF

- Describes the structure of a one-day practical skills course in the management of medical emergencies that is suitable for all members of the dental team.

- The educational rationale underpinning the course is explained.

- The paper highlights the benefits of team training.

This paper describes a practical skills one day course in the 'management of medical emergencies' which is aimed at fulfilling the requirements for training for dentists and DCPs as defined by the Resuscitation Council UK and prefaced by the GDC.

\section{INTRODUCTION}

The General Dental Council has identified medical emergencies training as one of the 'core' subjects for dentists and dental care professionals (DCPs). ${ }^{1,2}$ The current recommendations require a minimum of ten hours of education over each five year CPD cycle. Medical emergencies is also one of the 'key skills' for vocational dental practitioners ${ }^{3}$ and dental practitioners as defined by the Faculty of General Dental Practitioners. ${ }^{4}$ The Resuscitation Council (UK) issued a statement, with a preface by the GDC, which defined the standards for clinical practice and training in medical emergencies and resuscitation. ${ }^{5}$ All dentists and DCPs have access to basic life support (BLS) training, some have access to training in the use of automated external defibrillators (AEDs), but this does not fulfil the requirements to train in the 'assessment of the sick patient' as recommended by the Resuscitation Council, ${ }^{5}$ nor does it promote any confidence or competence in the management of a 'non arrest' situation. The course outlined below provides a template for

\footnotetext{
${ }^{1 *}$ Consultant in Oral Surgery, ${ }^{2}$ Consultant in Restorative Dentistry, Liverpool University Dental Hospital, Pembroke Place, Liverpool L3 5PS

*Correspondence to: Dr M. Colette Balmer

Email:m.c.balmer@liverpool.ac.uk
}

\section{Refereed Paper}

Accepted 7 March 2008

DOI: 10.1038/sj.bdj.2008.300

${ }^{\circ}$ British Dental Journal 2008; 204: 453-456 team training in medical emergencies that satisfies contemporaneous recommendations and training requirements and can be easily transferred to the work environment.

\section{EDUCATIONAL RATIONALE}

The ability to manage a medical emergency requires several key elements:

- Theoretical knowledge

- Practical clinical skills

- Confidence.

Theoretical knowledge will consist of prior knowledge, together with active re-enforcement on the day of the course. Any practical skill is acquired through demonstration and repetition. This exemplifies methodology promulgated by Peyton and Allery (1998) in their 'Hierarchy of skills' domain'6 shown in Figure 1.

Skill acquisition is taught by the 'four stage approach' described by Peyton, ${ }^{7}$ and adopted by the Resuscitation Council (UK) for their courses. This methodology consists of:

1. Demonstration of the skill at normal speed

2. Repetition of the skill with full explanation

3. The demonstrator performs the skill with the learner providing the explanation and being questioned on key issues

4. The learner carries out the skill under close supervision, describing each step before it is taken.

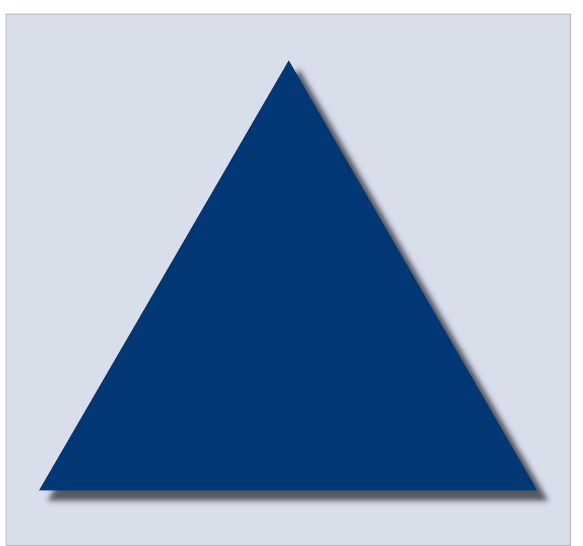

Fig. 1 'Hierarchy of Skills' domain' Peyton and Allery (1998) ${ }^{6}$

Dentists and DCPs cannot acquire and maintain the skills necessary for the management of medical emergencies on real patients; the use of simulators combined with role-play is therefore essential. This provides a 'safe' environment to promote active learning and allows for repetition of procedures as required to increase both competence and confidence.

\section{COURSE STRUCTURE}

The course consists of three components: lectures, skill stations and scenario training.

Theoretical/Didactic component: The aims and objectives of the course are explained to all participants prior to short presentations on:

1. The assessment and management of the airway in the conscious and unconscious patient

2. The indications for the use of 
emergency drugs and routes of administration

3. The significance of abnormal pulses, cardiac rhythms; cardiac arrest rhythms and defibrillation

4. Paramedic transfer and protocols.

Individual Skill Stations: Participants are divided into groups of six, with practice teams encouraged to remain together. Each group rotates through the four skill stations, each taking approximately 40 minutes; the details are given in Table 1. All the skill stations reinforce and explore the information imparted in the previous lectures.

\section{Station 1: Airway management}

All dentists and DCPs should know how to competently manage an airway and how to administer supplemental oxygen, recognise when airway adjuncts may be necessary, and be able to provide adequate and effective ventilations if necessary. Airway simulators are used and a variety of oxygen delivery systems and airway adjuncts are available for skill acquisition.

\section{Station 2: Pulses, cardiac rhythms and defibrillation}

The ability to correctly locate a pulse is a skill that is often assumed, rather than one which is taught. Variations in the rate and rhythm of a pulse can be diagnostic of certain conditions and it is essential that dentists and DCPs understand the significance of clinical findings. A computer controlled advanced life support (ALS) manikin is used for this station. This dummy has central palpable pulses and is attached to a cardiac monitor allowing visualisation of the rhythm that generates the abnormal pulse rates. The cardiac arrest rhythms are demonstrated, and the relevance of the shockable rhythms is discussed. The safe use of an AED is demonstrated and all participants take turns to use the AED appropriately.

\section{Station 3: Drug presentation and routes of administration}

There are many different presentations of emergency drugs and all require different degrees of preparation and equipment. All the different presentations

\section{Table 1 Practical skills training}

\begin{tabular}{l|l}
\hline Skill station & Skills included \\
\hline $\begin{array}{l}\text { Airway management } \\
\text { Choking, airway assessment, oxygen delivery systems (venturi masks, non- } \\
\text { rebreather masks), opening airways (jaw thrust, head tilt chin lift), insertion } \\
\text { of oropharyngeal and nasopharyngeal airways, use of pocket masks, use of } \\
\text { bag/valve masks (one handed and two handed), demonstration of insertion of } \\
\text { laryngeal masks and endotracheal tubes. }\end{array}$ \\
$\begin{array}{l}\text { Pulses, cardiac } \\
\text { rhythms and } \\
\text { defibrillation }\end{array}$ & $\begin{array}{l}\text { peripheral and central pulses, slow regular pulses (bradycardias and complete } \\
\text { heart block), slow irregular pulses (type 1 and type 2 heart block), fast regular } \\
\text { pulses (sinus tachycardia and VT), fast irregular pulses (atrial fibrillation), } \\
\text { cardiac arrest rhythms, use of an automated external defibrillator }\end{array}$ \\
\hline $\begin{array}{l}\text { Drug presentations } \\
\text { and administration } \\
\text { routes }\end{array}$ & $\begin{array}{l}\text { Preparation and delivery of drugs by inhalation, oral, transmucosal (buccal } \\
\text { lintra-nasal/sublingual), intramuscular; intravenous routes }\end{array}$ \\
\hline \multirow{2}{*}{$\begin{array}{l}\text { Assessment of } \\
\text { the sick patient }\end{array}$} & $\begin{array}{l}\text { A-airway (practical skills acquired in separate station) } \\
\text { B-breathing: rate, depth, chest expansion, accessory muscles, } \\
\text { demonstration of upper and lower airway obstruction by the } \\
\text { manikin producing the relevant noises } \\
\text { C-circulation: pulses (already covered in separate station), } \\
\text { blood pressure, capillary refill time } \\
\text { D-disability: level of consciousness (AVPU), pupil reaction, } \\
\text { monitoring of blood glucose } \\
\text { E-exposure: rashes, ankle oedema, relevance of preventing heat loss in shock }\end{array}$ \\
\hline
\end{tabular}

Table 2 Scenarios used for training

\begin{tabular}{l|l}
\hline - Chest pain/myocardial infarction & - Respiratory arrest \\
\hline $\begin{array}{l}\text { - VF/VT arrest (algorithm for non-shockable } \\
\text { arrest also covered here) }\end{array}$ & - Conscious and unconscious hypoglycaemia \\
\hline - Anaphylaxis & - Epilepsy \\
\hline - Panic attack & $\begin{array}{l}\text { Drug overdose with a CNS depressant (eg a } \\
\text { benzodiazepine) }\end{array}$ \\
\hline - Asthma &
\end{tabular}

of emergency drugs are demonstrated and participants assemble or prepare the different formats. Participants then practise administering the drugs using simulators.

\section{Station 4: Assessment of the sick patient}

The use of the approach is discussed. This station explores the assessment of the unwell patient using the systematic ABCDE approach. ${ }^{5}$ The order of assessment and the significance of the possible findings are discussed. Participants have the opportunity to practise any assessments they are not familiar with, such as taking blood pressure measurements.

\section{Scenario training}

The course instructors give a scenario demonstration so the participants can understand how the scenarios will work and how the previous information learnt is put into practice. The remainder of the course involves repeated scenario practice with each member of the group taking turns to manage the problem as team leader. The scenarios covered are listed in Table 2. Four separate rooms are used; three are set up as dental surgeries with a dental chair and the fourth mimics a waiting room. Whilst two or three clinical scenarios can be acted out in each room, the structure of each scenario is similar. A computer controlled ALS manikin that generates rhythms is used; this also has pulses, vocal and breath sounds. Appropriate resuscitation equipment is available, including an oxygen cylinder, venturi masks, airway adjuncts and bag/valve masks, an emergency drugs kit, a telephone and an automated external defibrillator. One participant will be the dentist and manage the emergency, one participant will be the DCP and a third will be the 
receptionist (who is trained in cardiopulmonary resuscitation). The three remaining participants, who will observe the scenario, are asked to positively critique the scenario. The instructor gives the 'dentist' or team leader the background details which includes the 'patient's' name, age, relevant medical history and the reason for attendance at the surgery. The instructor then delivers the voiceover for the manikin and describes what the 'patient' is feeling. The team leader takes any actions necessary to manage the situation. All the scenarios are run in 'real time'. The practical exercise ends with a transfer and handover to the paramedic; this allows the team leader to summarise the events that took place. A group discussion and feedback concludes each scenario.

At the end of the course all participants are encouraged to develop regular scenario training sessions within their own clinical practice settings.

\section{FEEDBACK FROM PARTICIPANTS}

To date 456 dentists, 88 DCPs and 48 VTs have attended the course, all of whom completed a standard evaluation form and were encouraged to give verbal feedback. The feedback has been very positive about the structure of the course and the efficacy of the skill stations and scenario practice. All participants felt that the 'teamwork' approach engendered on the course was extremely valuable, and many have stated that they intended to introduce regular scenario practice into their own clinical environments. On the evaluation forms $100 \%$ of the participants recorded that they enjoyed the course, that they felt the course was very relevant and useful, and they had a highly significant knowledge and skills gain.

\section{DISCUSSION}

Whilst participants enjoyed the course and felt it was very valuable the need for such a course and its educational validity need to be explored.

Is there a need for this type of course? The Resuscitation Council (UK) currently provides three categories of practical skill training in medical emergencies: BLS, immediate life support (ILS) and ALS. The prescriptive format of these courses is standardised and monitored by the Resuscitation Council. All concentrate on the management of cardiorespiratory arrest with a range of skills training that extends as each course is undertaken. Coulthard et al. ${ }^{8}$ considered whether ALS courses were appropriate for dentists and if it was necessary to design a bespoke course. This study concluded that there was no need to specifically tailor a course, however, the number of dentists (23) sampled in this study was small. ${ }^{8}$ Although dentists may benefit from an ALS course there is no provision for the initial management of a medical emergency in a primary care setting. In addition time spent on post resuscitation care in a hospital environment is not relevant. It is the authors' opinion that the feedback received from their courses would support the need for medical emergency courses designed specifically for the dental team.

Is this course format educationally valid? In order for an adult to learn successfully several factors have to be present as defined by Knowles ${ }^{9}$ who considered five principles to apply:

- As a person matures they become more self-directed

- Adults have accumulated experiences which can be a rich resource for learning

- Adults become ready to learn when they experience a need to know something

- Adults tend to be less subject-centred than children, they are increasingly problem-centred

- For adults the most potent motivators are internal.

As this course is designed to fulfil a specified need, is problem based and is aimed at increasing confidence as well as competence, the principles outlined above are fully achieved.

\section{The method of teaching}

Turner $^{10}$ stated the important principles of teaching a practical skill are:

- Teach progressively from the simple to the complex

- Teach the skills in the order in which they will be used

- Teach one technique at a time

- Employ continual re-enforcement
- Follow learning with practice

- Integrate cognitive and psychomotor learning

- Encourage confident employment of the skills.

The importance of these principles is re-iterated in the ALS Instructor course manual and is the methodology employed on all ALS and ILS courses. This is exactly the method of skill teaching used on this course by having individual skill stations allowing for repeated practice and psychomotor skill development, followed by the scenario practice to encourage 'confident employment of the skills' together with 'continual re-enforcement' and 'following learning with practice'.

The use of simulators and role-play is often criticised as being artificial, but this type of teaching is essential to develop confidence and competence in the diagnosis and management of a medical emergency. The use of 'responsive' manikins in a dental surgery setting provides a controlled and safe environment to enact the simulations using clinical equipment in 'real' time. This enables an effective team management strategy to be deployed.

\section{Difficulties}

To be effective this course needs to be designed and delivered by a team of four instructors who have extensive experience in both ALS teaching and dentistry. A thorough understanding of the candidate's background knowledge and experience is essential to produce an effective learning environment and provide realistic learning outcomes. The dental surgery environment is an essential component to add realism and ALS simulators are expensive and not easily portable, so considerable pre-planning is required. The ability to practise drug preparation carries an intrinsic cost, as does the 'disposable' equipment that is also used.

\section{CONCLUSIONS}

There is a specific need for training courses in the management of medical emergencies for dentists and DCPs. This course answers this need, is educationally valid, and has proved to be highly 
effective. All participants have reported an increase in both competence and confidence following the course, and have awareness of the importance of regular 'in house' scenario training.

The authors would like to thank members of the Resuscitation Training Department at University Hospitals Aintree for their contribution to both the development and continuing delivery of this course, and Dr Brian Grieveson, Postgraduate Dental Dean, for his financial support.
1. General Dental Council. CPD core guidance subjects for dentists. November 2006. www.gdc-uk.org

2. General Dental Council. CPD guidance for DCPs. July 2007. www.gdc-uk.org

3. Smile-on.com. Key skills in general dental practice 2005. www.smile-on.com

4. Howard P, Hall J. Guide to the coursework module of the MFGDP Examination. FGDP(UK) 2002.

5. Resuscitation Council (UK). Medical emergencies and resuscitation - standards for clinical practice and training for dental practitioners and dental care professionals in general dental practice. 2006. www.resus.org.uk/pages/MEdental.pdf

6. Peyton J W R, Allery L. Setting objectives. In Peyton J W R (ed). Teaching and learning in medical practice. p 60. Rickmansworth, Herts: Manticore Europe Limited, 1998.

7. Peyton J W R. The learning cycle.In Peyton J W R (ed). Teaching and learning in medical practice. $\mathrm{pp}$ 13-19. Rickmansworth, Herts: Manticore Europe Limited, 1998.

8. Coulthard P, Bridgman C M, Larkin A, Worthington $\mathrm{H}$ V. Appropriateness of a Resuscitation Council (UK) advanced life support course for primary care dentists. Br Dent J 2000; 188: 507-512.

9. Knowles M, associates. Andragogy in action. Houston: Gulf Publishing Co, 1984.

10. Turner S. Teaching CPR as a motor skill. Focus (Journal of Staff Development) 1987; spring: 80-82. 